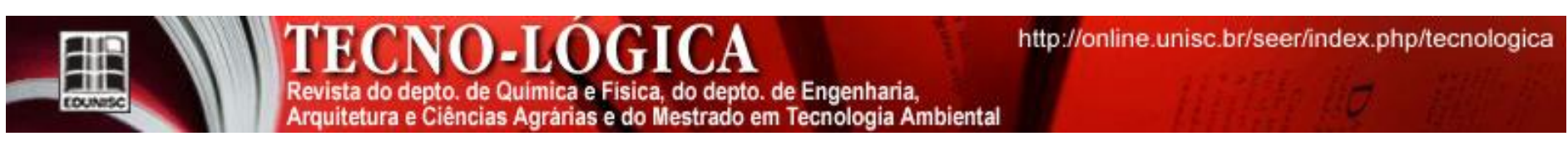

\title{
APLICAÇÃO DE CAMADAS COMPOSTAS DE MISTURAS DE ARENITO DECOMPOSTO E SOLOS EM PAVIMENTOS COM REVESTIMENTO PRIMÁRIO
}

\author{
Leandro Olivio Nervis ${ }^{*}$, Washington Peres Nuñez ${ }^{2}$ \\ 1 Professor, Departamento de Engenharias, Arquitetura e Ciências Agrárias, Universidade de Santa Cruz do Sul - UNISC, CEP \\ 96815-900, Santa Cruz do Sul-RS, Brasil. \\ 2 Professor, Departamento de Engenharia Civil, Universidade Federal do Rio Grande do Sul - UFRGS, CEP 90035-190, Porto \\ Alegre-RS, Brasil.
}

*E-mail: leandron@unisc.br

Recebido em: 27/10/2016 Aceito em:01/06/2017

\begin{abstract}
RESUMO
Os pavimentos com revestimento primário devem ser construídos a baixos custos e, ao mesmo tempo, apresentar também desempenho satisfatório quando submetidos às ações do tráfego e do clima. Sempre que possível, é preferível a utilização de materiais naturais disponíveis na região de entorno da obra, condicionada à viabilidade técnica, econômica e ambiental de sua aplicação. Neste artigo, é apresentado o resultado da avaliação do desempenho do revestimento primário de um trecho experimental implantado em Santana do Livramento-RS, Brasil. A região está inserida na unidade geomorfológica denominada de Depressão Central, numa formação geológica composta de arenito médio a fino, com subleito constituído de solo arenoso. Duas seções experimentais A e B foram estudadas. A primeira foi composta de uma mistura de dois solos e a segunda composta de uma mistura de solo com agregado natural de arenito. Foram efetuadas medições das deflexões do subleito e da pista pronta com utilização de viga Benkelman. Foram realizados ensaios de caracterização dos materiais (difratometria de raio-X, granulometria, peso específico dos grãos, limites de Atterberg e classificação MCT), ensaios para a avaliação da resistência ao desgaste e durabilidade do agregado de arenito (abrasão Los Angeles, sanidade e alteração de rochas água-estufa), ensaios de compactação, Índice de Suporte Califórnia - ISC, de cisalhamento direto e triaxiais de carga repetida para a obtenção de módulos de resiliência. Na avaliação do desempenho do trecho experimental foi monitorada a evolução de alguns defeitos típicos para o tipo de via (afundamento de trilha de roda, ondulações, buracos, atoleiros, perda de abaulamento, perda de espessura de revestimento e sulcos de erosão). Os resultados obtidos demonstraram que a seção A apresentou baixíssima durabilidade, não sendo recomendada sua aplicação futura. A seção B apresentou melhor desempenho, porém sua eventual aplicação futura deve ser precedida de uma avaliação de custo-benefício em comparação a outras possíveis alternativas.
\end{abstract}

Palavras-chave: Revestimento primário. Estradas vicinais. Misturas solo-agregado.

\section{Introdução}

As vias sem revestimento clássico (asfalto, concreto ou calçamento), providas ou não de revestimento primário, de acordo com o Departamento Nacional de Infraestrutura de Transportes - DNIT, representam $86,5 \%$ do total da malha viária nacional e $92,5 \%$ do Rio Grande do Sul [1].

Os pavimentos com revestimento primário devem ser construídos a baixos custos e, ao mesmo tempo, apresentar também desempenho satisfatório quando submetidos às ações do tráfego e do clima. Sempre que possível, é preferível a utilização de materiais naturais disponíveis na região de entorno da obra, condicionada à viabilidade técnica, econômica e ambiental de sua aplicação.

A preferência pelo uso de materiais naturais disponíveis a curtas distâncias repercute em economia e menores impactos ambientais por não haver necessidade de beneficiamento de materiais e devido à redução dos serviços de transporte. Do ponto de vista ambiental, isso impacta na redução de emissão de poluentes não somente de forma direta, mas também de forma indireta, o que inclui todo o processo de fabricação de equipamentos e de sua manutenção. Entretanto, os materiais têm que apresentar características adequadas, de forma que o revestimento primário apresente boa durabilidade.

O emprego de materiais inadequados exige manutenções mais frequentes das vias, com sucessivas extrações de material das áreas de empréstimo, que além de gerar custos, aumenta a dimensão das escavações e o assoreamento dos cursos d'água.

Um estudo envolvendo duas bacias hidrográficas localizadas em áreas agrícolas do Rio Grande do Sul demonstrou que embora as estradas ocupassem uma área 25 vezes menor que a das lavouras, elas contribuíam com um terço da produção de 
sedimentos nos mananciais [2]. A escolha inadequada do material de revestimento primário foi uma das causas apontadas.

Na região de Santana do Livramento-RS, constata-se uma carência muito grande de materiais in natura tais que, já de antemão, através de uma caracterização geológica e pedológica, não sejam previamente descartáveis para utilização no revestimento primário. Numa extensa área, o subleito é constituído de solo predominantemente arenoso, sendo vulnerável a sofrer desagregação e processos erosivos. Observou-se que a solução convencionalmente adotada, a qual consiste no agulhamento de uma camada granular de basalto decomposto de granulometria graúda importado da região geomorfológica vizinha sobre o subleito arenoso, além de ser bastante onerosa, em razão das grandes distâncias de transporte, não tem apresentado bons resultados. Por outro lado, há ocorrências frequentes de fontes de agregado natural de arenito e solos provenientes de sua desintegração, fato que motivou a realização da pesquisa.

A referida pesquisa consistiu na avaliação do desempenho de um trecho experimental de pavimento com revestimento primário concebido a partir de misturas de agregado natural de arenito e solo residual de arenito ("areia argilosa vermelha" oriunda do horizonte B), na proporção de 2:1 em volume. Dada a considerável heterogeneidade observada na área de empréstimo do agregado natural, a qual apresentou veios de material graúdo (cascalho) e outros de material mais fino, com aspecto arenoso, dividiu-se o trecho experimental em duas seções, A e B. Na seção A, utilizou-se o material mais fino, o qual se passou a designar de "solo arenoso", e na seção B, empregou-se o material mais grosseiro. Essa subdivisão teve por objetivo propiciar uma avaliação do desempenho das vias considerando as duas condições.

A partir de resultados de ensaios de laboratório e da prescrição contida em referências consultadas, é possível abstrair alguns indicativos de comportamento dos materiais empregados no revestimento primário e, então verificar, para o trecho experimental avaliado, se o desempenho observado se correlaciona ou não com tais indicativos.

\section{Metodologia}

\subsection{Implantação do trecho experimental}

O trecho experimental de pavimento com revestimento primário sobre o qual foi realizada a pesquisa foi implantado no Projeto de Assentamento (PA) Ibicuí, localizado em Santana do Livramento-RS, a aproximadamente $45 \mathrm{~km}$ a leste da sede desse município. No revestimento primário foram empregados materiais oriundos de duas áreas de empréstimo, sendo de uma delas extraída a areia argilosa vermelha e da outra o agregado natural de arenito, conforme descrito anteriormente. A primeira se situou no próprio PA Ibicuí, a uma distância média de $400 \mathrm{~m}$ do trecho experimental. A segunda se situou no PA Fidel Castro, às margens da BR 293, próxima à intersecção com a BR 158, a aproximadamente $40 \mathrm{~km}$ a nordeste da sede do município e numa distância média de $35 \mathrm{~km}$ do trecho experimental (Figura 1).

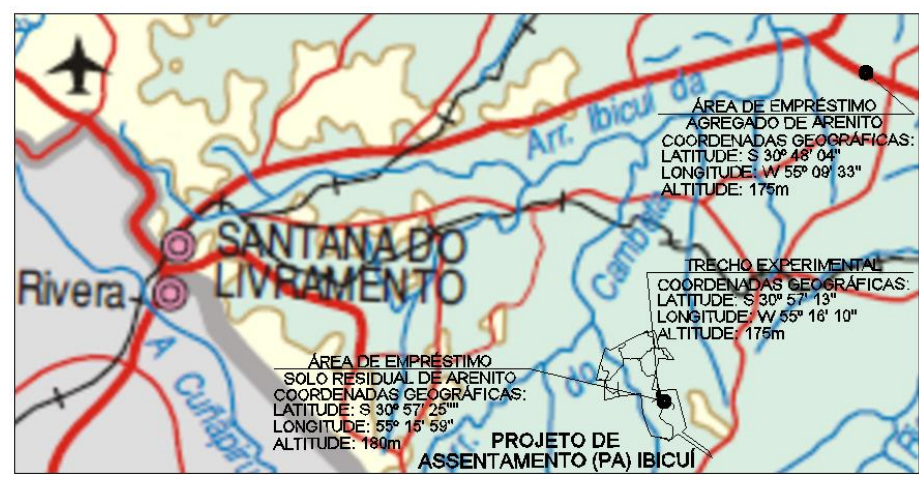

Figura 1- Localização do trecho experimental e das áreas de empréstimo no mapa físico.

O município de Santana de Livramento está localizado na região da campanha gaúcha, na fronteira oeste do estado do Rio Grande do Sul, no sul do Brasil. De acordo com informações obtidas através de consulta em material disponível no site da Secretaria de Planejamento e Gestão do estado do Rio Grande do Sul (SEPLAG/RS), o clima do estado é o temperado do tipo subtropical, classificado como mesotérmico úmido. O trecho experimental e as áreas de empréstimo se encontram inseridos dentro da unidade geomorfológica denominada de Depressão Central. No local, a temperatura média anual é de $18^{\circ} \mathrm{C}$ e a precipitação pluviométrica média anual é de 1500 a 1600mm [3].

Através de consulta ao Mapa de Biomas elaborado pelo Instituto brasileiro de Geografia e Estatística - IBGE, verificouse que a área de estudo está compreendida no bioma Pampa. De acordo com nota técnica que acompanha o mapa, esse bioma se caracteriza por clima chuvoso, sem período seco sistemático, marcado pela frequência de frentes polares e temperaturas negativas no período de inverno. Predomina no local uma vegetação rasteira do tipo herbácea/arbustiva. $O$ relevo é aplainado e suave ondulado, caracterizado pela presença das chamadas coxilhas [4].

De acordo com o mapa geológico elaborado pelo Serviço Geológico do Brasil - CPRM, a área pertence à formação geológica Parambóia do grupo Passa Dois, éon Fanerozóico, era Paleozólica, período Permiano, composta de arenito médio a fino $[5]$.

Com relação à pedologia, constatou-se que o trecho experimental e a área de empréstimo de solo pertencem às classes denominadas de argissolo vermelho-amarelo e argissolo vermelho, respectivamente, e no caso da área de empréstimo do 
pedregulho de arenito, trata-se de um neossolo regolítico. Os argissolos são geralmente profundos a muito profundos, variando de bem drenados a imperfeitamente drenados, sendo que as cores vermelha e amarela indicam ambientes bem drenados. Os mesmos apresentam um perfil com uma sequência de horizontes A-Bt-C ou A-E-Bt-C, onde o horizonte Bt é do tipo B textural. Esse horizonte, por ser significativamente mais argiloso do que os subjacentes, torna esse tipo de perfil pedológico bastante vulnerável a processos erosivos, sendo agravada essa condição para os argissolos originados do arenito, o que é o caso presente. O termo "Neossolo" lembra solos "novos", pouco desenvolvidos. São solos rasos ou profundos, apresentando no perfil uma sequência de horizontes A-R, A-C, A-C-R, A-Cr-R, O-R ou H-C, onde o horizonte designado pela notação $\mathrm{Cr}$ representa um saprólito. Pode, eventualmente, apresentar horizonte B de pouca espessura. São solos desenvolvidos a partir dos mais diversos tipos de rochas e encontrados nas mais diversas condições de relevo e drenagem. Os Neossolos Regolíticos apresentam o horizonte $\mathrm{A}$ assentado sobre a rocha totalmente alterada e contato com a rocha em profundidade maior que $50 \mathrm{~cm}$ a partir da superfície, admitindo horizonte B com espessura menor que $10 \mathrm{~cm} \mathrm{[6].}$

Em todos os perfis, verificou-se a ocorrência de uma camada superficial, de $0,10 \mathrm{~m}$ a $1,00 \mathrm{~m}$ de espessura, composta de areia fina com pouca matéria orgânica, porém em quantidade suficiente para conferir uma tonalidade cinza escura. No local de implantação do trecho experimental, sob a camada superficial, foi encontrada uma camada de areia argilosa vermelha e amarela que se estende até a profundidade de aproximadamente $2,00 \mathrm{~m}$, na qual a escavação da trincheira foi interrompida. $\mathrm{Na}$ área de empréstimo do solo residual de arenito, existe sob a camada superficial uma camada de aproximadamente 1,50 a 2,00m de areia argilosa vermelha (material utilizado) e, na sequência, a presença de uma camada de areia rosada que se estende até o fundo da escavação. $\mathrm{Na}$ área de empréstimo do agregado de arenito, encontrou-se, sob a camada superficial, uma camada (material utilizado) de espessura variando entre 1,00 a 3,00m, constituída desde fragmentos de arenito até solo arenoso oriundo da intemperização dessa rocha, com cores diversas, sendo tal camada assente sobre a rocha de origem. Em nenhum dos perfis observou-se a ocorrência do nível de água freático.

Conforme exposto anteriormente, averigou-se que a área de empréstimo de pedregulho apresentou uma considerável heterogeneidade, exibindo veios de material excessivamente graúdo e de material mais fino, com aspecto arenoso (Figura 2). Em razão disso, decidiu-se subdividir o trecho experimental em duas seções. Na primeira seção, denominada seção A, a camada de revestimento primário foi constituída de uma mistura composta do material mais fino extraído da área de empréstimo do cascalho de arenito (Figura 2-a) e do solo residual de arenito, na proporção de 2:1 em volume. A segunda seção, denominada de seção B, foi constituída de uma mistura composta do material mais grosseiro extraído da área de empréstimo do agregado natural de arenito (Figura 2-b) e do solo residual de arenito, também na proporção de 2:1 em volume. Para a seção A, mirouse uma espessura do revestimento para a ordem de $10 \mathrm{~cm}$, com a finalidade de avaliar o desempenho de uma camada mais esbelta. Para a seção B, em função do diâmetro do agregado graúdo, buscou-se atingir $15 \mathrm{~cm}$ de espessura da camada.

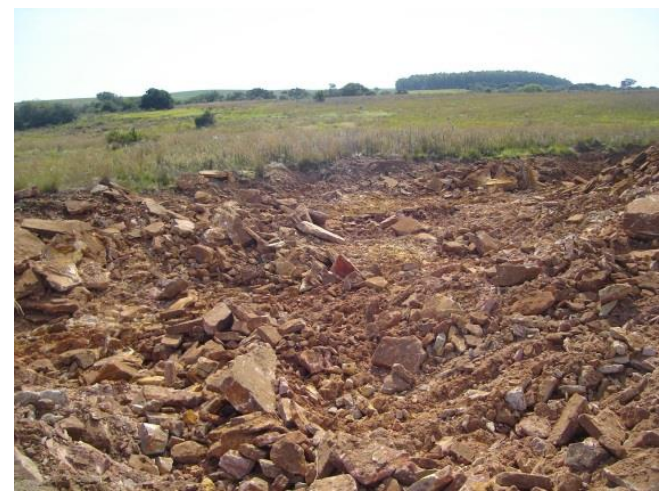

(a)

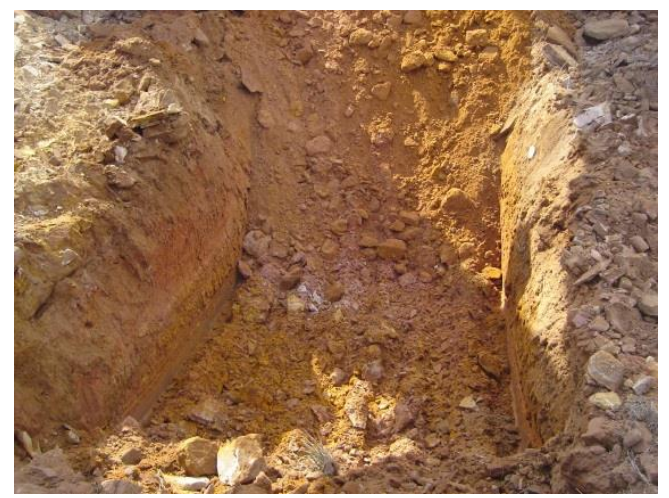

(b)

Figura 2- Área de empréstimo do agregado natural de arenito. (a) predominância de material graúdo; (b) predominância de material mais fino (areia).

As seções A e B foram executadas com $100 \mathrm{~m}$ de extensão por $8 \mathrm{~m}$ de largura total (computando-se as sarjetas) e 6 $\mathrm{m}$ de plataforma de rolamento. A seção A está situada num segmento reto e plano, apresentando declividades longitudinais de 0 a $1 \%$, enquanto a seção B compreende um trecho curvo e possui declividades longitudinais de $1 \%$ a $9 \%$ (Figura 3). 

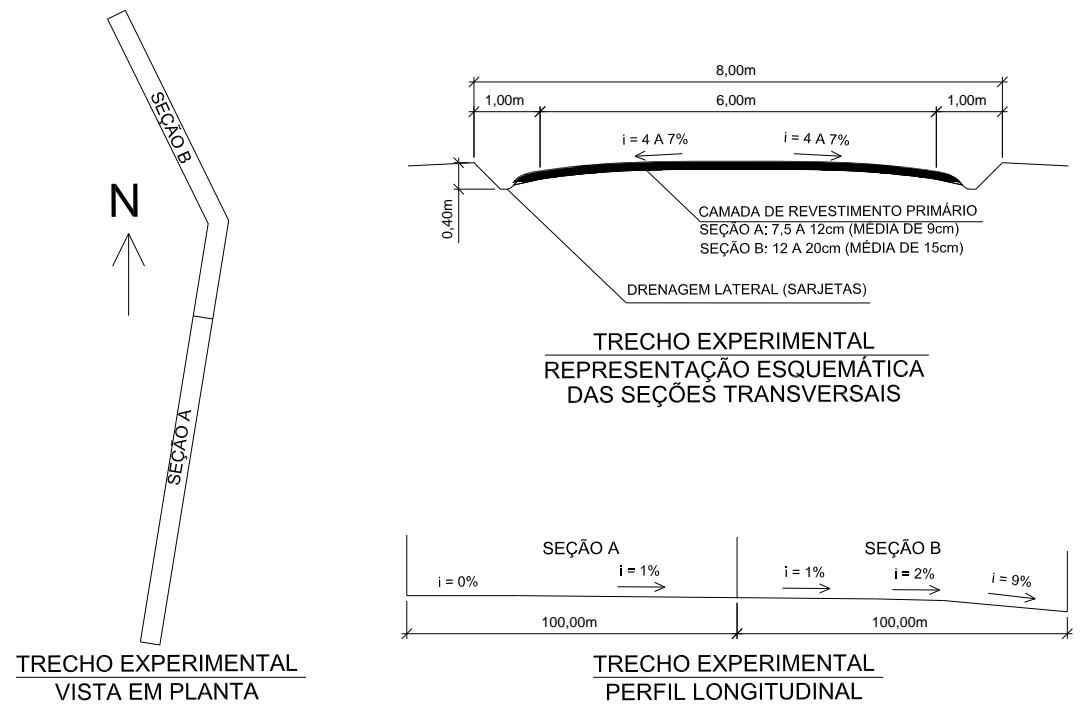

Figura 3- Representação Geométrica Esquemática (sem escala) do Trecho Experimental

O trecho experimental foi construído na data de 01/04/09, empregando-se as etapas executivas enumeradas a seguir:

1) determinação da umidade ótima de compactação da mistura da seção A;

2) medição das deflexões do subleito com utilização de viga Benkelman;

3) disposição e espalhamento dos materiais oriundos da jazida de agregado de arenito;

4) disposição e espalhamento do solo residual de arenito;

5) escarificação para promover a mistura;

6) compactação com a utilização de rolos do tipo péde-carneiro e liso;

7) verificação do grau de compactação para a seção A;

8) medição das deflexões da pista, das espessuras e do abaulamento.

A seção A (Figura 4-a) ficou com uma espessura final da camada de revestimento entre 7,5 a $12,0 \mathrm{~cm}$ (média de $9,0 \mathrm{~cm}$, desvio padrão de $1,7 \mathrm{~cm}$ e coeficiente de variação igual a 0,19$)$ e abaulamento entre 4 e $7 \%$. A seção B (Figura 4-b) ficou com uma espessura de 12,0 a $20,0 \mathrm{~cm}$ (média de $15,0 \mathrm{~cm}$, desvio padrão de $2,4 \mathrm{~cm}$ e coeficiente de variação igual a 0,16 ) e abaulamento entre 4 e $7 \%$, exceto na borda direita no trecho em curva.

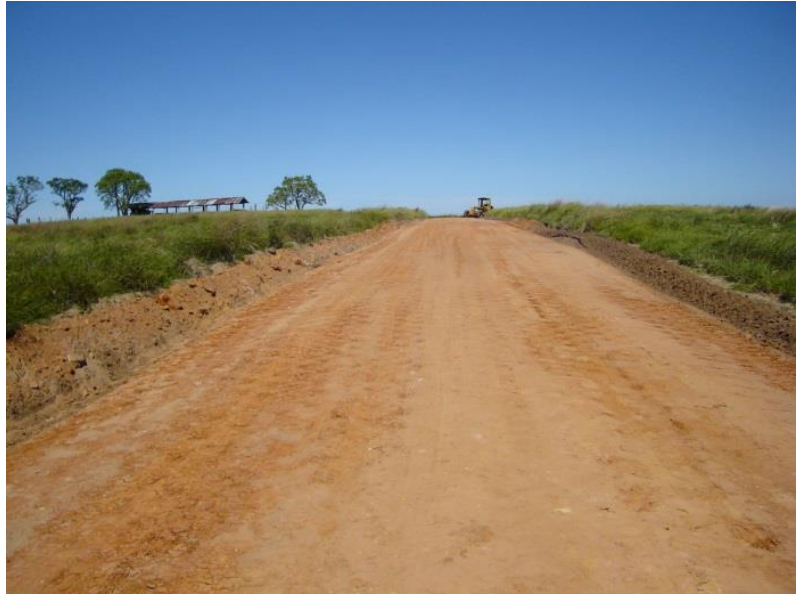

(a)

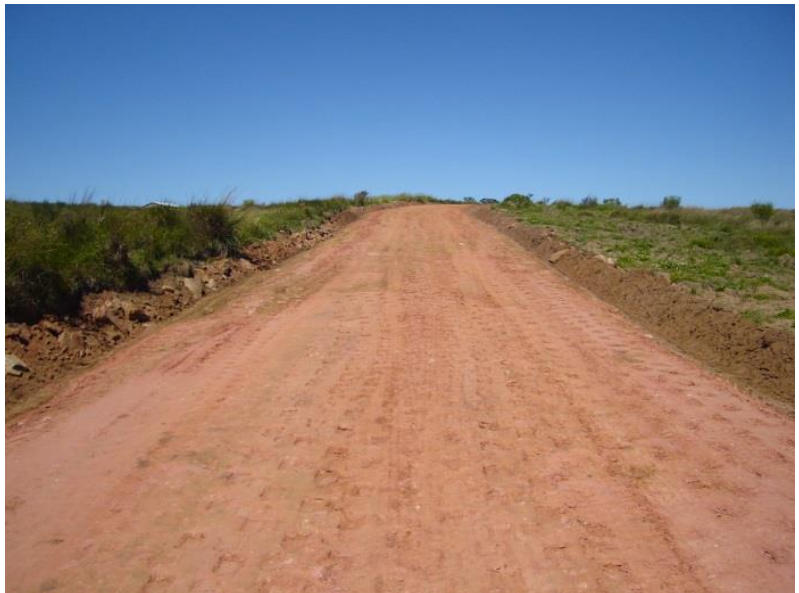

(b)

Figura 4 - Fotos do trecho experimental. (a) seção A; (b) seção B. 


\subsection{Realização de ensaios de campo}

Realizou-se 1 ensaio de compactação (5 pontos), empregando-se a energia normal de Proctor, para obter os parâmetros de compactação da composição de solos utilizada na seção A, seguindo-se para tal as normas NBR 6457:1986 [7] e NBR 7182:1986 [8].

Para o controle da qualidade da compactação na seção A utilizou-se o Método da Areia, prescrito pela norma DNER-ME 092/94 [9], sendo realizadas avaliações em dois pontos distribuídos ao longo da seção.

Mediram-se as deflexões do subleito e da pista pronta com o uso de uma viga Benkelman analógica, alternadamente de $20 \mathrm{em} 20 \mathrm{~m}$ em ambas as trilhas, de forma intercalada, seguindo-se os procedimentos recomendados pela norma DNER-ME 024/94 [10].

\subsection{Realização de ensaios de laboratório}

Foram realizados ensaios de caracterização (difratometria de raio-X, granulometria, peso específico dos grãos, limites de Atteberg e de classificação MCT) para os solos utilizados nas composições da camada de revestimento primário e para o solo do subleito e um ensaio de difração de raio- $X$ no agregado de arenito utilizado na composição da camada de revestimento primário na seção $\mathrm{B}$. Os procedimentos empregados seguiram as recomendações das normas NBR 6457:1986 [7], NBR 7181:1984 [11], NBR 6459:1984 [12], NBR 7180:1984 [13], NBR 6508:1984 [14] e de Nogami e Villibor [15].

Também foram realizados ensaios voltados à aplicação da Especificação Expedita de Materiais para Vias Não Pavimentadas - $4^{\text {a }}$ Aproximação proposta por D’ávila, Hax e Freitas [16].

Para a avaliação da resistência ao desgaste e durabilidade do agregado de arenito, foram realizados ensaios de abrasão Los Angeles, sanidade e alteração de rochas água-estufa, seguindo-se respectivamente as recomendações das normas DNER-ME 035/98 [17], DNER-ME 089/94 [18] e CESP.MRL-02 [19].

Foi refeito, em laboratório, ensaio de compactação (5 pontos) do material proveniente da composição de solos da camada de revestimento primário da seção A, empregando-se a energia normal de Proctor, para fins de verificação e para submeter os corpos de prova obtidos ao ensaio de determinação do Índice de Suporte Califórnia - ISC ou CBR (California
Bearing Ratio) e expansão. Foram também submetidos a estes mesmos ensaios todos os demais solos envolvidos, inclusive $o$ do subleito. Para tal, seguiram-se os procedimentos recomendados pelas normas NBR 6457:1986 [7], NBR 7182:1986 [8] e NBR 9895:1987 [20].

Para a determinação dos parâmetros de resistência c' e ø' da composição de solos empregados na seção A e do solo do subleito, foram realizados ensaios de cisalhamento direto. Para cada material ensaiou-se três corpos de prova, aplicando-se tensões normais de 200, 400 e $600 \mathrm{kPa}$. Os procedimentos empregados para a realização dos ensaios seguiram as recomendações feitas por Head [21], além das normas BS 1377-90 [22] e ASTM D3080-90 [23].

Por fim, foram realizados ensaios triaxiais de carga repetida, seguindo-se as recomendações da norma AASHTO T307-99 [24], com a finalidade de avaliar o comportamento resiliente da composição de solos empregados na camada de revestimento primário da seção A e do solo do subleito. Foram realizados dois ensaios para cada material.

A partir da análise dos resultados de ensaios de laboratório, das prescrições com base na classificação MCT [16] e da Especificação Expedita de Materiais para Vias Não Pavimentadas - $4^{\text {a }}$ Aproximação proposta por D'ávila, Hax e Freitas [16] , foram abstraídos indicativos de comportamento dos materiais empregados no revestimento primário do trecho experimental. Posteriormente, verificou-se, para o trecho experimental avaliado, se o desempenho observado se correlaciona ou não com tais indicativos, buscando-se com isso contribuir com a definição de critérios para a seleção de materiais para emprego em revestimento primário.

\subsection{Avaliação de desempenho do trecho experimental}

Para avaliar o desempenho do trecho experimental, realizaram-se inspeções de campo aplicando-se procedimentos baseados na metodologia da inspeção visual detalhada (Detailed Visual Inspection DVI) [25]. Tal metodologia consiste, basicamente, em registrar o tipo, a densidade e a severidade de cada defeito observado. Os tipos de defeitos definidos como os de ocorrência mais comum para o tipo de via em análise foram os seguintes: afundamento de trilha de roda, ondulações, buracos ("panelas"), atoleiros, perda de abaulamento, perda de espessura de revestimento e sulcos de erosão. Cada parâmetro do DVI é avaliado em escala de cinco pontos, e as condições são classificadas pela densidade do defeito expressa na percentagem da 
superfície da área $(<10 \%, 10-50 \%$ e $>50 \%$, de forma geral) e/ou pela sua severidade, por exemplo, no caso, das ondulações em baixo $(<2,0 \mathrm{~cm})$, média $(2,0-5,0 \mathrm{~cm})$ e severa $(>5,0 \mathrm{~cm})$. O valor médio de cada defeito varia na escala de 0 a 5 e terá, para cada um desses valores, as condições da estrada, conforme mostra a Tabela 1.

Tabela 1. RCS/DVI:Escala e Classificação da Condição da Estrada. \begin{tabular}{c|c|c|c|c|c}
\hline Escala & $0-1,0$ & $1,1-2,0$ & $2,1-3,0$ & $3,1-4,0$ & $4,1-5,0$ \\
\hline
\end{tabular} \begin{tabular}{l|l|l|l|l|l}
\hline Class. & Excelente & Bom & Regular & Ruim & Falido \\
\hline
\end{tabular}

Foram realizadas três inspeções para a avaliação do desempenho da pista experimental, nas datas de 18/06/09, 18/08/09 e 16/12/09 (respectivamente, 78, 139 e 259 dias após a construção).

Durante o período de monitoramento, ocorreu, de forma já prevista, um tráfego consideravelmente excedente àquele que seria o normal esperado para a via quando em funcionamento. Estrategicamente, o trecho foi implantado numa localização tal que, além da ocorrência do tráfego normal, ocorreu sobre o mesmo o transporte de todo o material e funcionários necessários para a implantação de vias situadas numa posição posterior ao referido trecho. Foi possível estimar o volume de tráfego atuante sobre a via e, então calcular, o número equivalente de repetições de carga $-\mathrm{N}$, utilizando-se para tal os fatores de equivalência de carga do DNIT [26]. Estimou-se também o volume de tráfego anual previsto correspondente a uma situação de utilização da via em condições normais, ou seja, sem o excedente de carga oriundo da existência da obra, resultando o mesmo em 7,5 x $10^{3}$. Com posse disso, calculou-se o período correspondente de tráfego da situação imposta à situação normal. Os resultados são expostos na Tabela 2.

Tabela 2. Número equivalente de repetições de carga do eixo padrão de $8,2 \mathrm{t}-\mathrm{N}$ atuante sobre o trecho experimental.

\begin{tabular}{c|c|c|c}
\hline $\begin{array}{c}\text { Data da } \\
\text { inspeção }\end{array}$ & $\begin{array}{c}\text { Dias } \\
\text { transcorridos }\end{array}$ & $\mathbf{N}$ & $\begin{array}{c}\text { Período } \\
\text { correspondente } \\
\text { (meses) }\end{array}$ \\
\hline $18 / 06 / 09$ & 78 & $8,6 \times 10^{3}$ & 14 \\
\hline $18 / 08 / 09$ & 139 & $1,5 \times 10^{4}$ & 24 \\
\hline $16 / 12 / 09$ & 259 & $1,9 \times 10^{4}$ & 30 \\
\hline
\end{tabular}

Por se tratar de uma via com revestimento permeável, a ação das chuvas tem efeito direto no eventual surgimento de defeitos. Para tal, levou-se em conta na avaliação de desempenho a intensidade das precipitações pluviométricas acumuladas desde a construção do trecho experimental até a data de cada inspeção, cujos valores estão registrados na Tabela 3 .
Tabela 3. Precipitações pluviométricas acumuladas da data da construção da pista experimental (01/04/09) até a data de cada inspeção.

\begin{tabular}{c|c|c}
\hline $\begin{array}{c}\text { Data da } \\
\text { inspeção }\end{array}$ & $\begin{array}{c}\text { Dias } \\
\text { transcorridos }\end{array}$ & $\begin{array}{c}\text { Precipitação } \\
\text { pluviométrica } \\
\text { acumulada } \\
(\mathbf{m m})\end{array}$ \\
\hline $18 / 06 / 09$ & 78 & 152 \\
\hline $18 / 08 / 09$ & 139 & 270 \\
\hline $16 / 12 / 09$ & 259 & 1.172 \\
\hline
\end{tabular}

\section{Apresentação e análise dos resultados}

\subsection{Ensaios de campo e de laboratório}

Nas Tabelas 4 e 5 são apresentados resumos dos resultados obtidos nos ensaios de campo e laboratório, respectivamente.

\begin{tabular}{|c|c|c|c|c|c|c|c|}
\hline \multirow{3}{*}{\multicolumn{3}{|c|}{ Ensaios/Propriedades }} & \multicolumn{4}{|c|}{ Seções } & \multirow{3}{*}{$\begin{array}{c}\text { Mistura } \\
\text { de } \\
\text { Solos }\end{array}$} \\
\hline & & & \multicolumn{2}{|c|}{$\mathbf{A}$} & \multicolumn{2}{|c|}{$\mathbf{B}$} & \\
\hline & & & Subleito & $\begin{array}{c}\text { Pista } \\
\text { Pronta }\end{array}$ & Subleito & \begin{tabular}{|c|} 
Pista \\
Pronta
\end{tabular} & \\
\hline \multirow{2}{*}{ 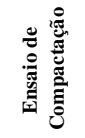 } & \multicolumn{2}{|c|}{ Umidade ótima (\% ) } & - & - & & - & 11,0 \\
\hline & \multicolumn{2}{|c|}{$\begin{array}{c}\text { Peso específico } \\
\text { aparente } \operatorname{seco}\left(\mathrm{kN} / \mathrm{m}^{3}\right)\end{array}$} & - & - & & - & 18,50 \\
\hline \multirow{3}{*}{ 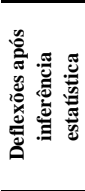 } & \multicolumn{2}{|c|}{$\begin{array}{c}\text { Média } \\
\left(\mathrm{mm} \times \mathbf{1 0}^{-2}\right)\end{array}$} & 150,7 & 109,3 & 98,0 & 80,9 & - \\
\hline & \multicolumn{2}{|c|}{$\begin{array}{c}\text { Des vio padrão } \\
\left(\mathrm{mm} \times 10^{-2}\right)\end{array}$} & 40,6 & 30,6 & 34,9 & 22,0 & - \\
\hline & \multicolumn{2}{|c|}{$\begin{array}{c}\text { Coeficiente de } \\
\text { variação }\end{array}$} & 0,27 & 0,28 & 0,36 & 0,27 & - \\
\hline \multirow{4}{*}{ 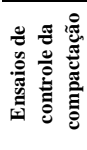 } & \multirow{2}{*}{$\mathrm{GC}(\%)$} & P1 & - & 100,6 & - & - & - \\
\hline & & $\mathbf{P 2}$ & - & 100,9 & - & - & - \\
\hline & \multirow{2}{*}{$\begin{array}{c}\text { Des vio de } \\
\text { umidade (\%) }\end{array}$} & P1 & - & $-0,3$ & - & - & - \\
\hline & & $\mathbf{P 2}$ & - & $-0,5$ & - & - & - \\
\hline
\end{tabular}

As umidades ótimas e pesos específicos aparentes secos máximos obtidos são típicos de solos com granulometria predominantemente arenosa [27]. Diferenças pouco expressivas foram observadas entre o ensaio realizado a campo (no caso da mistura de solos) e aquele de checagem feito em laboratório.

O grau de compactação determinado nos dois pontos distribuídos ao longo da seção A apontou uma excelente qualidade de compactação.

O valor da deflexão média do subleito foi consideravelmente maior na seção A do que na seção B. Observou-se que, em ambas as seções, a introdução da camada de revestimento conferiu uma importante redução nos valores das deflexões médias, sendo essa redução mais significativa na seção A. 
Tabela 5. Resumo dos resultados dos ensaios de laboratório.

\begin{tabular}{|c|c|c|c|c|c|c|c|}
\hline \multirow{2}{*}{\multicolumn{3}{|c|}{ Ensaios/Propriedades }} & \multicolumn{5}{|c|}{ Materiais } \\
\hline & & & \multirow{2}{*}{\begin{tabular}{|c|}
$\begin{array}{r}\text { Agregado } \\
\text { de Arenito }\end{array}$ \\
-
\end{tabular}} & \multirow{2}{*}{$\begin{array}{c}\begin{array}{c}\text { Solo } \\
\text { do } \\
\text { Subleito }\end{array} \\
0\end{array}$} & \multirow{2}{*}{$\begin{array}{c}\begin{array}{c}\text { Solo } \\
\text { Arenoso }\end{array} \\
1\end{array}$} & \multirow{2}{*}{$\begin{array}{c}\begin{array}{c}\text { Areia } \\
\text { Argilosa } \\
\text { Vermelha }\end{array} \\
0\end{array}$} & \multirow{2}{*}{$\begin{array}{c}\begin{array}{c}\text { Mistura de } \\
\text { Solos }\end{array} \\
1\end{array}$} \\
\hline \multirow{7}{*}{ 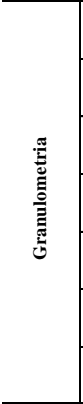 } & \multicolumn{2}{|c|}{$\begin{array}{l}\% \text { Pedregulho } \\
(>2 \mathrm{~mm})\end{array}$} & & & & & \\
\hline & \multicolumn{2}{|c|}{$\begin{array}{l}\text { \% Areia grossa } \\
(2 \mathrm{~mm} \text { a } 0,6 \mathrm{~mm})\end{array}$} & - & 1 & 9 & 1 & 4 \\
\hline & \multicolumn{2}{|c|}{$\begin{array}{l}\text { \% Areia média } \\
\text { (2mm a 0,6mm) }\end{array}$} & - & 8 & 20 & 8 & 15 \\
\hline & \multicolumn{2}{|c|}{$\begin{array}{c}\text { \% Areia fina } \\
(0,6 \mathrm{~mm} \text { a 0,06mm) }\end{array}$} & - & 77 & 59 & 54 & 62 \\
\hline & \multicolumn{2}{|c|}{$\begin{array}{c}\% \text { Silte } \\
(0,06 \mathrm{~mm} \text { a 0,002 mm }) \\
\end{array}$} & - & 7 & 4 & 8 & 3 \\
\hline & \multicolumn{2}{|c|}{$\begin{array}{l}\% \text { Argila } \\
(<0,002 \mathrm{~mm})\end{array}$} & - & 7 & 7 & 29 & 15 \\
\hline & \multicolumn{2}{|c|}{$\begin{array}{c}\text { Tipo de } \\
\text { granulometria }\end{array}$} & - & $\begin{array}{c}\text { Graduação } \\
\text { Uniforme }\end{array}$ & $\begin{array}{c}\text { Graduação } \\
\text { Uniforme }\end{array}$ & $\begin{array}{c}\text { Graduação } \\
\text { Descontínua }\end{array}$ & $\begin{array}{c}\text { Graduação } \\
\text { Descontínua }\end{array}$ \\
\hline \multicolumn{3}{|c|}{$\begin{array}{l}\text { Peso Es pecífico dos Grãos - } \gamma_{\mathrm{s}} \\
\left(\mathbf{k N} / \mathbf{m}^{3}\right)\end{array}$} & - & 25,65 & 25,93 & 26,13 & 25,89 \\
\hline \multirow{6}{*}{ 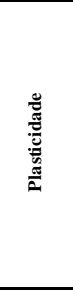 } & \multicolumn{2}{|c|}{$\begin{array}{l}\text { Limite de Liquidez - } \\
\text { LL (\%) }\end{array}$} & - & 13,4 & 20,4 & 30,2 & 22 \\
\hline & \multicolumn{2}{|c|}{\begin{tabular}{|c} 
Limite de Plasticidade \\
-LP $(\%)$ \\
\end{tabular}} & - & 9,9 & 19,7 & 17,6 & 13,9 \\
\hline & \multicolumn{2}{|c|}{\begin{tabular}{|c|} 
Índice de Plasticidade \\
IP $(\%)$
\end{tabular}} & - & 3,5 & 0,7 & 12,6 & 8,1 \\
\hline & \multicolumn{2}{|c|}{$\begin{array}{c}\text { Classificação segundo } \\
\text { Caputo (1988) }\end{array}$} & - & $\begin{array}{c}\text { Fracamente } \\
\text { Plástico }\end{array}$ & $\begin{array}{c}\text { Fracamente } \\
\text { Plástico }\end{array}$ & $\begin{array}{l}\text { Medianamente } \\
\text { Plástico }\end{array}$ & $\begin{array}{l}\text { Medianamente } \\
\text { Plástico }\end{array}$ \\
\hline & \multicolumn{2}{|c|}{\begin{tabular}{|l|} 
Classificação SUCS \\
\end{tabular}} & - & SP & SP & SP & SP \\
\hline & \multicolumn{2}{|c|}{ Classificação HRB } & - & A-2-4 & A-2-4 & A-6 & A-2-4 \\
\hline \multirow{2}{*}{ 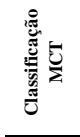 } & Ensaio pac & Irão & - & $\begin{array}{c}\text { Solo no } \\
\text { limite de } \\
\text { LA para } \\
\text { NA }\end{array}$ & \begin{tabular}{|c} 
Solo no \\
limite de LA \\
para NA
\end{tabular} & $\begin{array}{c}\text { Solo no limite } \\
\text { de LA para } \\
\text { NA }\end{array}$ & - \\
\hline & Método exp & eedito & - & LA'-LG' & LA'-LG' & NG & - \\
\hline 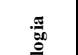 & Fração gr: & aúda & $\begin{array}{l}\text { Quartzo } \\
\text { Hematita }\end{array}$ & Quartzo & $\begin{array}{c}\text { Quartzo } \\
\text { Magnetita }\end{array}$ & $\begin{array}{l}\text { Quartzo } \\
\text { Hematita }\end{array}$ & - \\
\hline 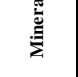 & Fração fi & & $\begin{array}{c}\text { Hidrotalcita } \\
\text { Esmectita } \\
\text { Illita }\end{array}$ & $\begin{array}{l}\text { Esmectita } \\
\text { Illita } \\
\text { Caolinita }\end{array}$ & $\begin{array}{l}\text { Esmectita } \\
\text { Illita } \\
\text { Caolinita }\end{array}$ & $\begin{array}{l}\text { Esmectita } \\
\text { Caolinita } \\
\text { Illita }\end{array}$ & - \\
\hline & Contração & (mm) & - & 1,0 & 1,3 & 2,7 & 1,8 \\
\hline & & $5^{\prime}$ & - & 0 & 1 & 3 & 2 \\
\hline$\overline{2}$ & & $10^{\prime}$ & - & 0 & 2 & 3 & 2 \\
\hline 五 & Penetração & $15^{\prime}$ & - & 0 & 2 & 3 & 2 \\
\hline 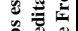 & $(\mathbf{m m})$ & $30^{\prime}$ & - & 0 & 2 & 3 & 2 \\
\hline 悉 & & $2 \mathrm{~h}$ & - & 0 & 2 & 3 & 2 \\
\hline & & $24 \mathrm{~h}$ & - & 0 & 2 & 3 & 2 \\
\hline & Resistência & a seco & - & Baixa & Baixa & Alta & Média \\
\hline Abras & são los angeles & (\%) & 43,69 & - & - & - & - \\
\hline & Sanidade (\%) & & 20,6 & - & - & - & - \\
\hline & $\%$ Perda de & \#2" & 0,7 & - & - & - & - \\
\hline ฐ & Peso & \# 1/2" & 2,0 & - & - & - & - \\
\hline 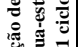 & $\begin{array}{c}\% \\
\text { Partículas }\end{array}$ & \# 2" & 0 & - & - & - & - \\
\hline$\frac{\vec{E}}{4}$ & $\begin{array}{c}\text { que rompem } \\
\text { manualmente }\end{array}$ & \# 1/1/2" & 83 & - & - & - & - \\
\hline & Umidade ótin & na (\%) & - & 10,5 & 10,0 & 16,0 & 11,3 \\
\hline 范 & $\begin{array}{r}\text { Peso espec } \\
\text { aparente seco }\end{array}$ & $\begin{array}{l}\text { ífico } \\
\left(\mathrm{kN} / \mathrm{m}^{3}\right)\end{array}$ & - & 19,12 & 19,00 & 17,95 & 18,64 \\
\hline 产 & ISC ou CBF & $2(\%)$ & - & 22,0 & 10,9 & 9,6 & 10,7 \\
\hline & Expansão & $(\%)$ & - & 0,17 & 0,11 & 0,37 & 0,14 \\
\hline & isaios de & $\mathbf{c}^{\prime}(\mathbf{k P a})$ & - & 13,2 & - & - & 31,8 \\
\hline cisalhar & amento direto & $\sigma^{\prime}\left({ }^{\circ}\right)$ & - & 34,1 & - & - & 28,9 \\
\hline Ensaios & s triaxias de & Modelo & - & argiloso & - & - & $\begin{array}{l}\text { arenoso }(\mathrm{CP} 1) \mathrm{e} \\
\text { constante }(\mathrm{CP} 2)\end{array}$ \\
\hline & fa repetida & K1 & - & 42,12 & - & - & 59,53 e 105,43 \\
\hline & & K2 & - & $-0,10$ & - & - & $0,22 \mathrm{e} 0$ \\
\hline
\end{tabular}

O material do subleito apresentou uma granulometria uniforme, na qual predomina a presença de areia fina, com baixas porcentagens de silte e argila.
Quanto aos materiais utilizados na composição de solos da seção A, tem-se que o solo arenoso também apresentou uma distribuição granulométrica uniforme, com predominância de areia fina, porém, com uma porcentagem importante de areia média e areia grossa e baixas quantidades de silte e argila. Já, a areia argilosa vermelha, exibiu uma porcentagem um pouco maior que metade do solo amostrado de areia fina e uma porcentagem de $29 \%$ de argila, sendo pobre a concentração de partículas de diâmetros intermediários, fato que confere uma granulometria descontínua.

Dentro das finalidades de se optar por uma composição de materiais para empregar na camada de revestimento primário, buscou-se, a partir dos materiais disponíveis no local, uma mistura com porcentagens adequadas de agregados graúdos, areia e finos. Os finos teriam a função de preencher os vazios formados pela presença das partículas maiores, enquanto o material graúdo garantiria a capacidade de suporte da via. As argilas ainda exerceriam o papel de aglutinante, cimentando as frações de agregados e conferindo à camada uma boa densidade [28]. Para tal, é necessário avaliar de antemão as características individuais de cada fração dos materiais constituintes da mistura em relação às propriedades específicas, a qual não se resume a uma simples análise granulométrica. Na seção $\mathrm{A}$, a composição foi desprovida de materiais de granulometria graúda, buscando-se assim investigar qual o impacto disso na capacidade de suporte da via.

Com relação aos ensaios voltados à classificação MCT, os resultados obtidos através do ensaio padrão e do ensaio expedito foram distintos. Desta forma, foram levados em consideração somente os primeiros. Todos os solos envolvidos ficaram na transição das classificações LA e NA. Os materiais pertencentes ao grupo LA, por possuírem quantidades muito baixas de finos, podem ser relativamente permeáveis, pouco coesivos e pouco contráteis quando secos, mesmo quando bem compactados, características essas pouco desejáveis para bases de pavimentos, apesar de apresentarem capacidade de suporte e módulo de resiliência elevados [15]. Já os pertencentes ao grupo NA, quando compactados, apresentam capacidade de suporte de pequena a média, porém, geralmente, são muito erodíveis [15]. Mesmo coexistindo nesses solos indicativos de possíveis problemas, há de se considerar que os mesmos se constituem no que foi encontrado de melhor na região em questão, após uma investigação geotécnica inicial que envolveu consultas preliminares a mapas geológicos e pedológicos e abertura mecânica de trincheiras.

Empregando-se a Especificação Expedita de 
Materiais para Vias Não Pavimentadas - $4^{\mathrm{a}}$ Aproximação proposta por D'ávila, Hax e Freitas [16], tem-se que o solo do subleito é inadequado para funcionar como camada final, o que implica na necessidade de introdução de revestimento primário. $\mathrm{O}$ solo arenoso e a argila arenosa são por si só inadequados para emprego no revestimento primário, o mesmo ocorrendo para a mistura de solos empregada na seção A do trecho experimental.

Constatou-se uma carência na literatura de valores limites de abrasão Los Angeles e perda de massa da amostra submetida ao ensaio de sanidade para o caso específico da aplicação do material em camadas de revestimento primário. Em termos gerais, limites de 55\% e $12 \%$, respectivamente, têm sido referenciados nas fontes consultadas [29; 30]. Desta forma, o valor obtido para a abrasão Los Angeles se enquadra dentro do limite, enquanto que a perda de massa da amostra submetida ao ensaio de sanidade supera o limite referenciado.

Os resultados obtidos no ensaio de alteração de rocha do agregado de arenito apontaram que o grau de desintegração sofrido pelo material foi baixo, sendo coerente com a mineralogia obtida no ensaio de difração de raio-X, cuja composição mineralógica do material, com presença de quartzo, indicou que o mesmo apresenta tendência a apresentar resistência aos processos de desintegração ocasionados pelos agentes do intemperismo, dificilmente se alterando nas condições normais de uso [31].

Os valores do índice de expansão obtidos nos ensaios foram muito baixos para todos os solos.

Nas regiões tropicais e subtropicais, a utilização de misturas que embora não atendessem as exigências tradicionais quanto a granulometria, CBR e plasticidade, tiveram, frequentemente, desempenho satisfatório quando utilizados como componentes solos de comportamento laterítico [15]. A imposição granulométrica tradicional não leva em conta a natureza dos componentes finos da mistura solo-agregado. Entretanto, a prática tem mostrado que no caso de misturas contendo finos lateríticos, a deficiência granulométrica fica compensada pela melhor qualidade dos referidos finos. Desta forma, torna-se possível a utilização de materiais com granulometria descontínua ou mesmo sem possuir fração acima de 2,00 mm. Quanto às questões referentes à resistência dos grãos, capacidade de suporte e expansão dos materiais, é mais apropriado o uso de métodos que levem em conta as propriedades de deformabilidade dos materiais, em substituição aos ensaios de CBR e abrasão Los Angeles [15]. Na presente pesquisa, tal questão ficou enaltecida quando o solo do subleito, mesmo apresentando valor de CBR expressivamente maior do que a composição de solos utilizada no revestimento primário da seção A do trecho experimental, apresentou módulo de resiliência mais baixo do que esta.

\subsection{Desempenho do trecho experimental}

Nas Tabelas 6 e 7 são apresentados de forma resumida os resultados obtidos nas três inspeções realizadas a campo para as seções A e B, respectivamente.

De acordo com os resultados apresentados nas Tabelas 6 e 7, verifica-se que os defeitos de ondulações, buracos e atoleiros não se manifestaram durante $o$ período das inspeções.

Com relação ao afundamento de trilha de roda ATR, verificou-se que a evolução do surgimento desse defeito na seção A foi consideravelmente maior do que na seção B, conforme demonstrado no gráfico da Figura 5. Tal defeito pode estar ligado ao surgimento de deformações permanentes e/ou a ruptura por cisalhamento das camadas. Com base nas inspeções visuais realizadas a campo, constatou-se, claramente, que na seção A ocorreu a ruptura por cisalhamento do pavimento, pois os afundamentos foram acompanhados pelo solevamento lateral. Já na seção B ocorreram apenas deformações permanentes excessivas, sem ruptura por cisalhamento (Figura 6).

$\mathrm{Na}$ ocasião da primeira inspeção, a ruptura por cisalhamento do pavimento já havia ocorrido em parte da seção A, estando toda ela comprometida quando da segunda inspeção. Isso demonstrou que a solução empregada apresenta baixa durabilidade, pois o pavimento começa a apresentar rupturas por cisalhamento para valores de $\mathrm{N}$ menores que $8,6 \times 10^{3}$.

A seção B apresentou desempenho melhor que a seção A, sendo que afundamentos de trilha de roda da ordem de $30 \mathrm{~mm}$ foram observados para um $\mathrm{N}$ de aproximadamente $1,9 \times 10^{4}$. Os limites estabelecidos em diferentes referências diferem muito entre si, sendo considerados severos valores de $30 \mathrm{~mm}, 50 \mathrm{~mm}$ e $75 \mathrm{~mm}$ [25]. 
Tabela 6. Resumo dos resultados obtidos nas inspeções destinadas à avaliação da Seção A.

\begin{tabular}{|c|c|c|c|c|c|c|}
\hline \multirow[t]{2}{*}{ Defeito Avaliado } & \multicolumn{2}{|c|}{$\begin{array}{c}\text { Inspeção realizada em } \\
18 / 06 / 09 \\
\left(\mathrm{~N} \sim 8,6 \times 10^{3} \equiv 14 \text { meses }\right)\end{array}$} & \multicolumn{2}{|c|}{$\begin{array}{c}\text { Inspeção realizada em } \\
18 / 08 / 09 \\
\left(\mathrm{~N} \sim 1,5 \times 10^{4} \equiv 24 \text { meses }\right)\end{array}$} & \multicolumn{2}{|c|}{$\begin{array}{c}\text { Inspeção realizada em } \\
16 / 12 / 09 \\
\left(\mathrm{~N} \sim 1,9 \times 10^{4} \equiv 30 \text { meses }\right)\end{array}$} \\
\hline & $\begin{array}{c}\text { Classe de } \\
\text { Severidade }\end{array}$ & $\begin{array}{c}\text { Condição da } \\
\text { Estrada }\end{array}$ & $\begin{array}{c}\text { Classe de } \\
\text { Severidade }\end{array}$ & $\begin{array}{c}\text { Condição da } \\
\text { Estrada }\end{array}$ & $\begin{array}{c}\text { Condição da } \\
\text { Estrada }\end{array}$ & $\begin{array}{c}\text { Condição da } \\
\text { Estrada }\end{array}$ \\
\hline Afundamento de trilha de roda & 3,3 & $\begin{array}{c}\text { Ruim } \\
\text { (5 a } 32 \mathrm{~mm})\end{array}$ & 5,0 & $\begin{array}{c}\text { Falida } \\
(26 \mathrm{a} 80 \mathrm{~mm})\end{array}$ & $\mathrm{N}^{*}$ & $\mathrm{~N}^{*}$ \\
\hline Ondulações & 1,0 & Excelente & 1,0 & Excelente & 1,00 & Excelente \\
\hline Perda de abaulamento & 4,0 & Ruim & 5,0 & Falida & $\mathrm{N}^{*}$ & $\mathrm{~N}^{*}$ \\
\hline Perda de espessura de revestimento & 2,0 & Boa & 3,0 & Regular & $\mathrm{N}^{*}$ & $\mathrm{~N}^{*}$ \\
\hline Sulcos de erosão & 1,0 & Excelente & 1,0 & Excelente & 3,3 & Ruim \\
\hline Buracos & 1,0 & Excelente & 1,0 & Excelente & 1,0 & Excelente \\
\hline Atoleiros & 1,0 & Excelente & 1,0 & Excelente & 1,0 & Excelente \\
\hline
\end{tabular}

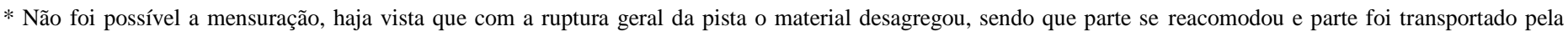
erosão.

Tabela 7. Resumo dos resultados obtidos nas inspeções destinadas à avaliação da Seção B

\begin{tabular}{|c|c|c|c|c|c|c|}
\hline \multirow[t]{2}{*}{ Defeito Avaliado } & \multicolumn{2}{|c|}{$\begin{array}{c}\text { Inspeção realizada em } \\
18 / 06 / 09 \\
\left(\mathrm{~N} \sim 8,6 \times 10^{3} \equiv 14 \text { meses }\right)\end{array}$} & \multicolumn{2}{|c|}{$\begin{array}{c}\text { Inspeção realizada em } \\
18 / 08 / 09 \\
\left(\mathrm{~N} \sim 1,5 \times 10^{4} \equiv 24 \text { meses }\right)\end{array}$} & \multicolumn{2}{|c|}{$\begin{array}{c}\text { Inspeção realizada em } \\
16 / 12 / 09 \\
\left(\mathrm{~N} \sim 1,9 \times 10^{4} \equiv 30 \text { meses }\right)\end{array}$} \\
\hline & $\begin{array}{c}\text { Classe de } \\
\text { Severidade }\end{array}$ & $\begin{array}{c}\text { Condição da } \\
\text { Estrada }\end{array}$ & $\begin{array}{c}\text { Classe de } \\
\text { Severidade }\end{array}$ & $\begin{array}{c}\text { Condição da } \\
\text { Estrada }\end{array}$ & $\begin{array}{c}\text { Condição da } \\
\text { Estrada }\end{array}$ & $\begin{array}{c}\text { Condição da } \\
\text { Estrada }\end{array}$ \\
\hline Afundamento de trilha de roda & 2,0 & $\begin{array}{c}\text { Boa } \\
(0 \text { a } 30 \mathrm{~mm}) \\
\end{array}$ & 2,4 & $\begin{array}{c}\text { Regular } \\
(0 \text { a } 30 \mathrm{~mm})\end{array}$ & 5,0 & $\begin{array}{c}\text { Falida } \\
(22 \mathrm{a} 43 \mathrm{~mm})\end{array}$ \\
\hline Ondulações & 1,0 & Excelente & 1,0 & Excelente & 1,0 & Excelente \\
\hline Perda de abaulamento & 2,0 & Boa & 4,0 & Ruim & 4,0 & Ruim \\
\hline Perda de espessura de revestimento & 2,0 & Boa & 4,0 & Ruim & 5,0 & Falido \\
\hline Sulcos de erosão & 1,1 & Boa & 1,3 & Boa & 3,2 & Regular \\
\hline Buracos & 1,0 & Excelente & 1,0 & Excelente & 1,0 & Excelente \\
\hline Atoleiros & 1,0 & Excelente & 1,0 & Excelente & 1,0 & Excelente \\
\hline
\end{tabular}

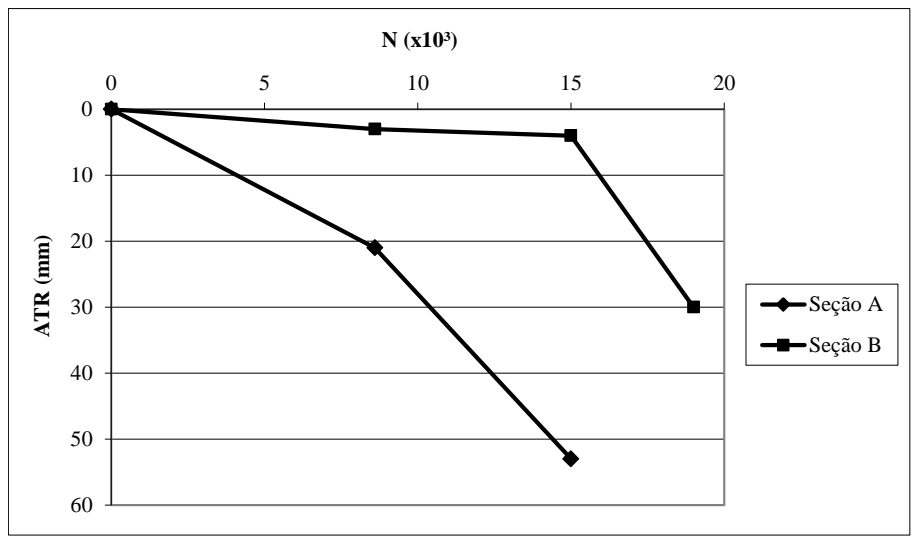

Figura 5 - Gráfico de evolução dos afundamentos de trilha de roda médios em função do tráfego.
Os resultados demonstraram que a fração graúda (agregado de arenito) presente na composição empregada na seção $\mathrm{B}$ foi responsável por conferir ao revestimento primário uma maior capacidade de suporte do que na seção A, composta por uma mistura de solos, a qual apresentou ruptura ao cisalhamento de forma precoce. Isso demonstrou que os solos empregados não apresentaram qualidade suficiente para compensar estruturalmente a ausência da fração graúda

Com relação à perda de abaulamento, tem-se que o defeito está relacionado com as deformações permanentes que ocorrem em toda a largura da pista. Conforme resultados obtidos, tal defeito se agravou mais rapidamente e em maior escala na seção A do que na seção B.

Quanto à perda de espessura de revestimento, observa-se que em ambas as seções, o defeito se manifestou de forma semelhante, sendo ligeiramente superior na seção B. Na seção A, no entanto, antes de ser atingida a classe de severidade máxima de 5,0 (condição falida), ocorreu a ruptura por cisalhamento da 
pista, impossibilitando a obtenção de um quarto valor.

Observou-se que em ambas as seções do trecho experimental o defeito "sulcos de erosão" tem se manifestado em magnitudes semelhantes, sendo ligeiramente superior na seção A, na qual atingiu o valor máximo de 3,3 (condição ruim) contra 3,2 (condição regular) na seção B. É importante salientar que, conforme apresentado no item 2.2, a seção A foi implantada num trecho praticamente plano, com declividades longitudinais de 0 a $1 \%$, enquanto a seção $\mathrm{B}$ ficou localizada num trecho com declividades longitudinais de $1 \%$ a $9 \%$. Isso significa que a seção B foi mais solicitada com relação ao surgimento do defeito. Com isso, conclui-se que esta se mostrou mais durável com relação aos processos erosivos do que aquela.

(a)

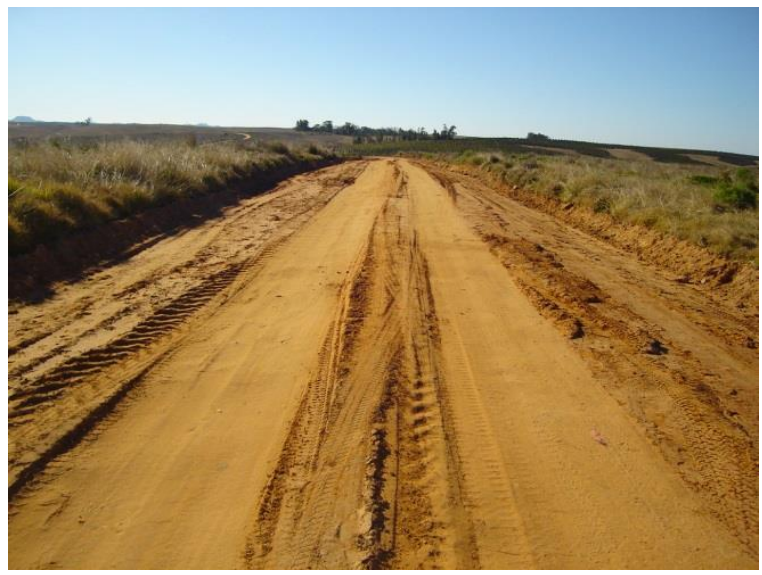

(b)

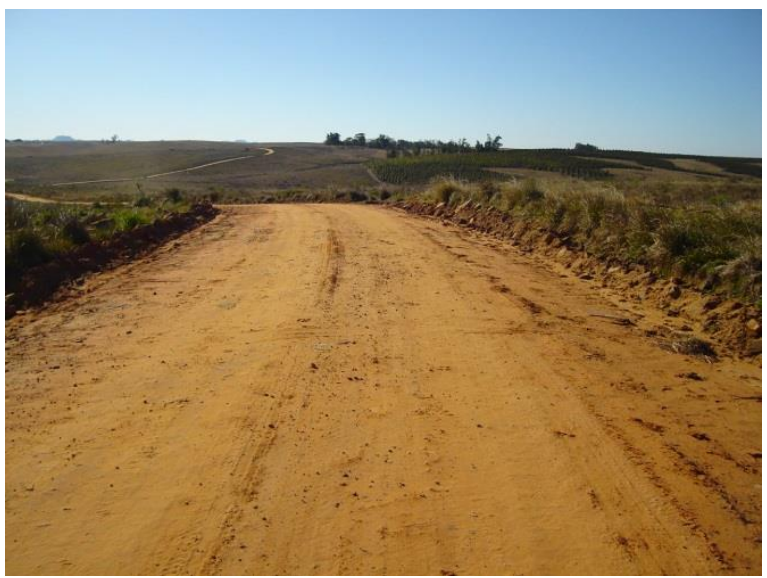

Figura 6 - fotos do trecho experimental após ser submetido às ações do tráfego e do clima. (a) seção A na data de 29/07/09 e (d) seção B na data de 29/07/09.

\section{Conclusões}

A seção A do trecho experimental apresentou baixa durabilidade, sendo que a ruptura por cisalhamento ocorreu de maneira precoce. Desta forma, a adoção de tal solução não é recomendada. Já a seção $\mathrm{B}$, apresentou desempenho melhor que a seção $\mathrm{A}$, porém sua adoção futura na região deve ser avaliada em função do custo-benefício dela em comparação a soluções que demandem a importação de materiais de maiores distâncias e da possibilidade da introdução de técnicas de melhoria dos solos. Não há registros que levem ao conhecimento dessa solução desde a realização do experimento aqui apresentado.

Conclui-se que o melhor desempenho da seção B, dado principalmente pela sua maior capacidade estrutural, é creditado à fração graúda (agregado de arenito) utilizada na mistura, sendo que os solos empregados na mistura da seção $\mathrm{A}$, por si só não apresentaram qualidade suficiente para compensar estruturalmente a ausência da fração graúda.

O indicativo de comportamento dos solos empregados abstraídas a partir da classificação MCT [15] e da Especificação Expedita de Materiais para Vias Não Pavimentadas - $4^{\mathrm{a}}$ Aproximação proposta por D’ávila, Hax e Freitas [16], as quais restringiam o emprego dos materiais para pavimentação, traduziram o desempenho observado em campo, validando, portanto, tais propostas para a seleção de solos para uso no revestimento primário para o caso do trecho experimental estudado. Conforme descrito anteriormente, os solos empregados não conferiram boa capacidade de suporte para a via, que no caso da seção B foi de certa forma suprida pelo material graúdo, apresentaram potencial erodível e a areia argilosa utilizada nas misturas não exerceu o poder aglutinante esperado, uma vez que o defeito de perda de espessura de revestimento se manifestou de maneira expressiva nas duas seções.

Os resultados obtidos no ensaio de molhagem/secagem do agregado de arenito apontaram que o grau de desintegração sofrido pelo material foi baixo confirmando o comportamento esperado para o material em função da sua mineralogia obtida no ensaio de difração de raio-X. Isso aponta que esse ensaio, embora ainda não tenham sido estabelecidos valores limites de referência, pode ter potencial aplicação para qualificar os agregados graúdos, em substituição ao ensaio de sanidade.

Para os materiais estudados, os valores de ISC e módulo de resiliência não apresentaram correlação, demonstrando que o ensaio de ISC não se mostra adequado para avaliação da deformabilidade elástica.

\section{APLICATION OF LAYERS COMPOSED OF MIXTURES OF WEATHERED SANDSTONE AND SOILS IN UNSURFACED GRAVEL ROADS}

ABSTRACT: The unsurfaced gravel roads should be built at low cost and, at the same time, also present a satisfactory 
performance when subjected to traffic and weather conditions. Whenever possible, preference should be given to the use of natural materials available in the surrounding area of the work, subject to technical, economic and environmental feasibility of their application. This paper presents the results of the assessment of the performance of an experimental stretch deployed in the town of Santana do Livramento, Brazil. The region is inserted into the geomorphological unit called the Central Depression, a geological formation composed of medium to fine sandstone with subgrade composed of sandy soil. Two experimental sections $\mathrm{A}$ and $\mathrm{B}$ were studied. The first consisted of a mixture of two soils and the second made up of a soil mixture with weathered sandstone. Deflection measurements were made of the subgrade and ready track with use of Benkelman beam. Characterization tests were conducted on materials (X-ray diffraction, grain size distribution test, particle density, Atteberg limits and classification MCT), tests for the evaluation of wear resistance and durability of weathered sandstone (Los Angeles abrasion test, sulfate soundness test and wet/dry cycles), compaction tests, California Bearing Ratio $\mathrm{CBR}$, direct shear and repeated load triaxial to obtain resilient modulus. In the evaluation of the performance of the experimental stretch, the evolution of some defects typical for the type of route was monitored (wheel track sinking, corrugations, potholes, bogs, loss of cross-section slope, thickness loss of wearing course and erosion channels). The results showed that Section A had very low durability, not recommended its future application. Section B performed better, but its possible future application must be preceded by a costbenefit assessment compared to other alternatives.

Keywords: Primary coating. Unsurfaced gravel roads. Soil-aggregates mixtures.

\section{Referências}

[1] BRASIL. Departamento Nacional de Infraestrutura de Transportes - DNIT. Divisão em Trechos do PNV, 2016. Disponível em: <http://www.dnit.gov.br/sistema-nacional-de-viacao/sistema-nacional-deviacao>. Acesso em: 25 abr. 2017.

[2] MINELLA, J. P. G. et al. Identificação e Implicações para a Conservação do Solo das Fontes de Sedimentos em Bacias Hidrográficas. Revista Brasileira de Ciência do Solo, Vol. 31, nº . 6, 2007. doi: 10.1590/S0100-06832007000600039. Disponível em: < http://www.scielo.br/scielo.php?script=sci_arttext\&pid=S010006832007000600039\&lng=en\&nrm=iso >. Acesso em: 23 abr. 2017.

[3] RIO GRANDE DO SUL. SEPLAG - Secretaria de Orçamento e Gestão. Governo do Estado do Rio Grande do Sul. Informações sobre Geografia Física, 2016. Disponível em <http://www.atlassocioeconomico.rs.gov.br/inicial>. Acesso em 19 out. 2016.

[4] BRASIL. Instituto Brasileiro de Geografia e Estatística - IBGE. Mapa de Biomas. Disponível em: <http://www.ibge.gov.br/home/presidencia/noticias/21052004biomashtml.shtm>. Acesso em: 19 out. 2016.

[5] BRASIL. CPRM - Serviço Geológico do Brasil. Mapa geológico do Rio Grande do Sul, 2008.
[6] Streck, E.V. et al. Solos do Rio Grande do Sul. 2. Ed. Porto Alegre: EMATER/ASCAR, 2008. 222 p

[7] Associação Brasileira de Normas Técnicas - ABNT. 1986. NBR 6457:1986: Amostras de solo - Preparação para ensaios de compactação e ensaios de caracterização. Rio de Janeiro: ABNT, 1986

[8] Associação Brasileira de Normas Técnicas - ABNT. NBR 7182:1986: Solo Ensaio de compactação. Rio de Janeiro: ABNT, 1986.

[9] Brasil. Departamento Nacional de Estradas de Rodagem - DNER. Diretoria de Desenvolvimento Tecnológico. Instituto de Pesquisas Rodoviárias - IPR. Divisão de Capacitação Tecnológica. DNER-ME 092/94 Solo - Determinação da massa específica aparente "in situ", com emprego do frasco de areia. Rio de Janeiro: Instituto de Pesquisas Rodoviárias - IPR, 1994. Disponível em: <http://ipr.dnit.gov.br/normas-e-manuais/normas/meetodo-de-ensaio-me/dnerme092-94.pdf>. Acesso em: 03 mar. 2008

[10] Brasil. Departamento Nacional de Estradas de Rodagem - DNER. Diretoria de Desenvolvimento Tecnológico. Instituto de Pesquisas Rodoviárias - IPR. Divisão de Capacitação Tecnológica. DNER-ME 024/94 Pavimento Determinação das deflexões pela viga Benkelman. Rio de Janeiro: Instituto de Pesquisas Rodoviárias - IPR, 1994. Disponível em: <http://ipr.dnit.gov.br/normas-e-manuais/normas/meetodo-de-ensaio-me/dnerme024-94.pdf>. Acesso em: 03 mar. 2008.

[11] Associação Brasileira de Normas Técnicas - ABNT. NBR 7181:1984: Análise granulométrica - Método de ensaio. Rio de Janeiro: ABNT, 1984.

[12] Associação Brasileira de Normas Técnicas - ABNT. NBR 6459:1984: Solo - Determinação do Limite de Liquidez. Rio de Janeiro: ABNT, 1984.

[13] Associação Brasileira de Normas Técnicas - ABNT. NBR 7180:1984: Solo - Determinação do Limite de Plasticidade. Rio de Janeiro: ABNT, 1984.

[14] Associação Brasileira de Normas Técnicas - ABNT. NBR 6508:1984: Grãos de solos que passam na peneira de $4,8 \mathrm{~mm}$ - Determinação da massa específica. Rio de Janeiro: ABNT, 1984

[15] NOGAMI, J.S. e VILLIBOR, D.F. Pavimentação de Baixo Custo com Solos Lateríticos. São Paulo: Villibor, 1995. 240 p.

[16] D’ÁVILA, A.M., HAX, S. E FREITAS, P.C. Especificação Expedita de Materiais para Vias Não Pavimentadas - $4^{\text {a }}$ Aproximação. In: XI CONGRESSO NACIONAL DE GEOTECNIA E IV CONGRESSO LUSO-BRASILEIRO DE GEOTECNIA, 2008, Coimbra, Portugal.

[17] Brasil. Departamento Nacional de Estradas de Rodagem - DNER. Diretoria de Desenvolvimento Tecnológico. Instituto de Pesquisas Rodoviárias - IPR. Divisão de Capacitação Tecnológica. DNER-ME 035/98 Agregados Determinação da abrasão Los Angeles. Rio de Janeiro: Instituto de Pesquisas Rodoviárias - IPR, 1998. Disponível em: <http://ipr.dnit.gov.br/normas-emanuais/normas/meetodo-de-ensaio-me/dner-me035-98.pdf >. Acesso em: 12 dez. 2008

[18] Brasil. Departamento Nacional de Estradas de Rodagem - DNER. Diretoria de Desenvolvimento Tecnológico. Instituto de Pesquisas Rodoviárias - IPR. Divisão de Capacitação Tecnológica. DNER-ME 089/94 Agregados - Avaliação da durabilidade pelo emprego de soluções de sulfato de sódio ou de magnésio. Rio de Janeiro: Instituto de Pesquisas Rodoviárias - IPR, 1994. Disponível em: <http://ipr.dnit.gov.br/normas-e-manuais/normas/meetodo-de-ensaio-me/dnerme089-94.pdf>. Acesso em: 12 dez. 2008.

[19] Companhia Energética de São Paulo - CESP. MRL-02. Ensaio de alteração de rocha água-estufa. Laboratório Central de Engenharia Civil/CESP,1990.

[20] Associação Brasileira de Normas Técnicas - ABNT. NBR 9895:1987: Solo - Índice de Suporte Califórnia. Rio de Janeiro: ABNT, 1987.

[21] HEAD, K. H. Manual of Soil Laboratory Testing. London: Pentech Press, 1982. $747 \mathrm{p}$. 
[22] British Standard Institution - BSI. BS 1377 - 90: Britsh Standard methods of test for soils for civil engineering purposes: part 7 - shear strength tests (total stress). London: BSI, 1990.

[23] American Society for Testing and Materials. ASTM D3080-90: Standard test method for direct shear test of soils under consolidated drained conditions. Montgomery County: ASTM, 1990.

[24] American Association of State Highway and Transportation Officials AASHTO. T307-99: Standard method for preparing and determining the triaxial resilient modulus of soils. Washington: AASHTO, 1999.

[25] FERREIRA, F. M. Uma Aplicação Comparativa de Métodos de Avaliação das Condições Superficiais de Estrada Não-Pavimentada. 2004. 222 f. Dissertação (Mestrado) - Universidade Estadual de Campinas, Campinas, 2004.

[26] BRASIL. Departamento Nacional de Infraestrutura de Transportes - DNIT. Diretoria de Planejamento e Pesquisa. Coordenação Geral de Estudos e Pesquisas. Instituto de Pesquisas Rodoviárias - IPR. Manual de Estudos de Tráfego. Rio de Janeiro: Instituto de Pesquisas Rodoviárias - IPR, 2006. Disponível em: <http://www1.dnit.gov.br/arquivos_internet/ipr/ipr_new/manuais/manual_estudos _trafego.pdf>. Acesso em: 19 out. 2016.

[27] PINTO, C. S. Curso Básico de Mecânica dos Solos. 2. Ed. São Paulo: Oficina de Textos, 2002. 359 p.

[28] KELLER, G.; SHERAR, J. Low-Volume Roads Engineering: Best Manegement Practices Field Guide. Washington: US Agency For International Development (USAID), 2003. 158 P.

[29] BERNUCCI et al. Pavimentação Asfáltica: Formação Básica para Engenheiros. Rio de Janeiro: Petrobrás: Abeda, 2007. 398 p.

[30] SÃO PAULO. Secretaria dos Transportes. Departamento de Estradas de Rodagem do Estado de São Paulo - DER/SP. ET-DE-P00/013 Revestimento Primário, 2006. Disponível em <ftp://ftp.sp.gov.br/ftpder/normas/ET-DE-P00013_A.pdf >. Acesso em 19 out. 2016.

[31] CAPUTO, H. P. Mecânica dos solos e suas aplicações. 6. ed. Rio de Janeiro: LTC, 1988, v. 1.244 p. 